\title{
The enhancement of salt stress tolerance by salicylic acid pretreatment in Arabidopsis thaliana
}

\author{
L.-L. YU ${ }^{1}$, Y. LIU ${ }^{1}$, F. ZHU ${ }^{3}$, X.-X. GENG ${ }^{1}$, Y. YANG ${ }^{1}$, Z.-Q. HE ${ }^{2 *}$, and F. XU ${ }^{1 *}$ \\ Applied Biotechnology Center, Wuhan University of Bioengineering, Wuhan 430415, P.R. China ${ }^{1}$ \\ Biotechnology Research Center, China Three Gorges University, Yichang 443002, P.R. China ${ }^{2}$ \\ College of Horticulture and Plant Protection, Yangzhou University, Yangzhou 225009, P.R. China
}

\begin{abstract}
Salicylic acid (SA) is an important plant hormone involved in the activation of defense responses against environmental stresses. However, there are still large of unsolved mysteries about how SA pretreatment affects the establishment of plant stress tolerance. In this study, application of SA at different concentrations and different times were conducted to investigate their effects on the response of Arabidopsis seedlings to salt stress. The pretreatment with 10 or $20 \mu \mathrm{M}$ SA for more than $6 \mathrm{~h}$ promoted Arabidopsis seedlings resistance to salt stress. On the other hand, pretreatment with $200 \mu \mathrm{M}$ SA reduced Arabidopsis resistance to salt stress and aggravated oxidative damage to the seedlings. At all concentrations used, SA pretreatment inhibited the total respiration and promoted reactive oxygen species (ROS) generation. However, the ROS content in 10 or $20 \mu \mathrm{M}$ SA pretreated seedlings decreased to the basal level within $6 \mathrm{~h}$ and high activities of antioxidant enzymes and alternative oxidase were maintained. Notably, the SA-enhanced salt stress resistance was significantly impaired by blocking alternative oxidase (AOX) pathway. Our findings indicate that SA-mediated salt stress response is in a dose- and time-dependent manner and that the effects were related to the induction of AOX capacity and antioxidant system.
\end{abstract}

Additional key words: alternative oxidase, antioxidant enzymes, reactive oxygen species, resistance index.

\section{Introduction}

Environmental stresses are often limiting for plant productivity (Kumar et al. 2015). In order to cope with such adverse situations, plants have evolved welldeveloped mechanisms that help to perceive the stress signal and enable optimal growth response (Verma et al. 2016). Phytohormones, such as salicylic acid (SA), have been shown to play critical roles in helping the plants to adapt to adverse environmental conditions (Miura and Tada 2014, Sharma 2014). The SA is one of a diverse group of phenolic compounds, consisting of an aromatic ring bearing a hydroxyl group or its functional derivative, is synthesized by plants and is induced after infection by many pathogens or abiotic stress (Fragniere et al. 2011, Pál et al. 2013). It has been reported that endogenous SA content increased by water deficit, low temperature, salt salinity, etc. (Scott et al. 2004, Sawada et al. 2006, Okuma et al. 2014). However, it is likely that the over-accumulation of endogenous SA triggers the overproduction of reactive oxygen generation (ROS), which results in stress sensitivity (Scott et al. 2004, Miura et al. 2013). Therefore, SA has been proposed to have a dual role in the regulation of plants response to stress conditions: lower SA accumulation plays a protective role in stress-induced oxidative damage, while higher amounts of SA have an adverse effects (Jayakannan et al. 2015). For instance, it was noted that SA-deficient $N a h G$ transgenic Arabidopsis plants displayed a higher adaptation to moderate salt stress, whereas the high-level SA Arabidopsis ecotype Cvi-0 showed a worse adaptation (Borsani et al. 2001, Cao et al. 2009).

Since SA is known to affect various physiological and biochemical activities of plants and has great potential to improve the stress tolerance of agriculturally important

Submitted 6 March 2019, last revision 21 October 2019, accepted 2 December 2019.

Abbreviations: AOX - alternative oxidase; APX - ascorbate peroxidase; CAT - catalase; DI - damage index; GPX - guaiacol peroxidase; MDA - malondialdehyde; MOE - molecular operating environment; Qi - quinone reduction; ROS - reactive oxygen species; RI resistance index; SA - salicylic acid; SHAM - salicylhydroxamic acid; SOD - superoxide dismutase.

Acknowledgements: This work was supported by the National Natural Science Foundation of China $(31400242,31900242,31500209$,

31271686) and the Outstanding Youth Science and Technology Innovation Team of Hubei Province, China (T201732).

* Corresponding authors; e-mails: feixu666@hotmail.com and zhq_he@163.com 
crops, large number of studies were carried out to elucidate the effect of exogenous SA on growth, physiology, and stress response of plants grown under adverse conditions. Notably, it has been proposed that the utility of SA rely on the concentration of the applied SA and the developmental stage of the plants (Miura and Tada 2014). In many previous studies, SA was applied at micromolar concentrations (Norman et al. 2004, Ashraf et al. 2010) rather than at millimolar concentrations (Maxwell et al. 2002, Gilliland et al. 2003), showing to be beneficial for plant growth and plant tolerance to environmental stresses. For example, when the applied SA concentration is less than $10 \mu \mathrm{M}$, it could significantly alleviate the decline in photosynthesis caused by salt stress in many plants (Stevens et al. 2006, Szepesi et al. 2009, Wasti et al. 2012), but in the case of 1 - $5 \mathrm{mM} \mathrm{SA}$ application, the opposite effects occurred (Nazar et al. 2011). The research of Lee et al. (2010) showed that the application of more than $100 \mu \mathrm{M}$ SA aggravated the inhibition of seed germination of Arabidopsis at high salinity, while less than $50 \mu \mathrm{M} \mathrm{SA}$ mitigated this inhibition.

In addition to the difference in exogenous SA concentration, SA pretreatment time was also different in previous studies. Generally, plants were pretreated with SA for $24 \mathrm{~h}$ followed by a variety of stress conditions (Khan et al. 2012, Palma et al. 2013, Singh et al. 2015). In addition, the application of SA in plants for $2 \mathrm{~d}$ (Palma et al. 2013), $7 \mathrm{~d}$ (Singh et al. 2015), $14 \mathrm{~d}$ (Bai et al. 2015), $21 \mathrm{~d}$ (Horváth et al. 2015) or more have also been implemented in the past. However, it is important to note that previous studies focused mainly on the effects of SA pretreatment on plant resistance after a certain concentration or a certain time. Less attention has been paid on the effects of different processing times of SA at a certain concentration on plants stress acclimation.

The aim of this study, therefore, is to further investigate the effects of pretreatment with different concentrations of SA on plant response to salt stress, and in particular to reveal the time effects of SA pretreatment on plant stress resistance. The changes in respiration rate, ROS production, and antioxidants enzyme activities were analyzed during SA pretreatment lasting $0-24 \mathrm{~h}$. In addition, the resistance index (RI) was calculated to evaluate the differences in the ability of plants stress acclimation. To investigate the inhibitory effect of SA on cellular respiration, the possible docking sites of SA in cytochrome $b c l$ were analyzed.

\section{Materials and methods}

Plant growth and chemical treatments: Seeds of Arabidopsis thaliana L. cv. Columbia (Col; wild-type) were surface-sterilized in $20 \%$ (v/v) commercial bleach for $20 \mathrm{~min}$, followed by six washes with sterile distilled water. The seeds were sown onto $1 / 2 \mathrm{MS}$ agar plates for germination. The plates with the seeds were placed at $4{ }^{\circ} \mathrm{C}$ in the dark for $48 \mathrm{~h}$ to improve germination uniformity before transfer to growth chambers with 16-h photoperiod, an irradiance of $150 \mu \mathrm{mol} \mathrm{m} \mathrm{m}^{-2} \mathrm{~s}^{-1}$ ), day/night temperatures $22 / 18{ }^{\circ} \mathrm{C}$, and a $70 \%$ relative humidity for $7 \mathrm{~d}$. Then, the seedlings were transferred from MS agar plates to pots containing Vermiculite, Perlite, and Soilrite mix (1:1:1 by volume). Pots were placed on the same condition in growth chamber.

For SA pretreatment, the four-week-old seedlings (rosette growth is almost complete) were sprayed with different concentrations of SA (Sigma, St. Louis, MO, USA) and the control seedlings were sprayed with deionized water. To study the affection of AOX inhibition on SAmediated plant response to stress, $1 \mathrm{mM}$ salicylhydroxamic acid (SHAM, Sigma), which is an inhibitor of alternative oxidase, was used in this experiment. For each treatment or independent experiment, at least 5 seedlings were used for experimental testing and analysis.

Salt stress treatment: To investigate the effects of SA pretreatment at different concentrations on plant response to salt stress, $200 \mathrm{mM} \mathrm{NaCl}$ was used in this study. Every two hours (from 0 to $24 \mathrm{~h}$ ) after pretreatment with different concentrations of SA, at least five seedlings from each treatment were transferred to salt stress. The desired salinity was maintained by irrigating the soil with $200 \mathrm{mM} \mathrm{NaCl}$ and the trays were also filled with the same concentration of saline solution. The saline solution in the tray was replaced twice every day in order to ensure the consistency of $\mathrm{NaCl}$ concentration. All analyses performed after $5 \mathrm{~d}$ of salt stress treatment.

Leaf respiration measurements: Respiratory oxygen consumption was measured using Clark-type electrodes (Hansatech, King's Lynn, UK) based on the methods of $\mathrm{Xu}$ et al. (2012). The leaves (0.05 g) were cut into small pieces, then pretreated with $5 \mathrm{~cm}^{3}$ of deionized water for $15 \mathrm{~min}$ in order to eliminate wound-induced respiration. Measurements were done at $25{ }^{\circ} \mathrm{C}$ in a final volume of $2 \mathrm{~cm}^{3}$ of phosphate buffer ( $\mathrm{pH} \mathrm{6.8)}$, and the cuvette was tightly closed to prevent diffusion of oxygen from the air. Inhibitors of the cytochrome pathway $(1 \mathrm{mM} \mathrm{KCN})$ and the alternative pathway ( $1 \mathrm{mM} \mathrm{SHAM}$ ) were used. The AOX pathway respiration is defined as $\mathrm{O}_{2}$ uptake rate in the presence of KCN that was sensitive to SHAM. Total respiration is defined as $\mathrm{O}_{2}$ uptake rate by samples without any inhibitors.

Ion leakage was measured according to the method of $\mathrm{Xu}$ et al. (2012). After measuring the conductivity, the samples were boiled for $15 \mathrm{~min}$ to achieve $100 \%$ ion leakage.

Malondialdehyde (MDA) content was measured according to the method of Sun et al. (2006). Approx. $0.2 \mathrm{~g}$ of fresh leaves were cut into small pieces and homogenized by the addition of $5 \mathrm{~cm}^{3}$ of $5 \%(\mathrm{~m} / \mathrm{v})$ trichloroacetic acid (TCA) in an ice bath. The homogenate was transferred into a tube and centrifuged at $1000 \mathrm{~g}$ and $4{ }^{\circ} \mathrm{C}$ for $10 \mathrm{~min}$. Aliquots of supernatant and $0.5 \%(\mathrm{~m} / \mathrm{v})$ thiobarbituric acid (TBA) in $20 \%$ TCA solution were added into a new tube. This mixture was incubated at $98^{\circ} \mathrm{C}$ for $40 \mathrm{~min}$, then cooled to room temperature and centrifuged at $8000 \mathrm{~g}$ for $5 \mathrm{~min}$. The supernatant was subjected to analysis with the spectrophotometer. The MDA content was calculated from the subtracted absorbance $\left(\mathrm{A}_{535}-\mathrm{A}_{600}\right)$ using the coefficient 
of absorbance of $155 \mathrm{mM}^{-1} \mathrm{~cm}^{-1}$.

Hydrogen peroxide content of leaves was measured as described by Velikova et al. (2000). Approx. $0.5 \mathrm{~g}$ of fresh leaves were cut into small pieces and homogenized in an ice bath with $5 \mathrm{~cm}^{3}$ of $0.1 \%(\mathrm{~m} / \mathrm{v})$ trichloroacetic acid (TCA). The homogenate was centrifuged at $12000 \mathrm{~g}$ and $4{ }^{\circ} \mathrm{C}$ for $20 \mathrm{~min}$ and $0.5 \mathrm{~cm}^{3}$ of the supernatant was added to $0.5 \mathrm{~cm}^{3}$ of $10 \mathrm{mM}$ potassium phosphate buffer ( $\left.\mathrm{pH} 7.0\right)$ and $1 \mathrm{~cm}^{3}$ of $1 \mathrm{M} \mathrm{KI}$. The absorbance of the supernatant was read at $390 \mathrm{~nm}$.

Measurement of leaf chlorophyll content: Leaf chlorophyll was extracted with $80 \%(\mathrm{v} / \mathrm{v})$ acetone from the fresh leaves and measured according to Lichtenthaler and Wellburn (1983).

Evaluation of damage index and resistance index of stressed seedlings: The damage index was categorized according to the methodology as follows:

Damage index (DI) $=\left[\mathrm{R}_{\mathrm{IL}}+\mathrm{R}_{\mathrm{MDA}}+\mathrm{R}_{\mathrm{H} 2 \mathrm{O2}}+\mathrm{R}_{\mathrm{CHL}}\right] / 4$; IL - ion leakage, CHL - chlorophyll.

$\mathrm{R}_{\mathrm{x}}$ : Decreased ratio of stressed samples relative to normal growing samples.

For $\mathrm{R}_{\mathrm{IL}}, \mathrm{R}_{\mathrm{MDA}}$, and $\mathrm{R}_{\mathrm{H} 2 \mathrm{O} 2}$ calculation, $\mathrm{R}_{\mathrm{x}}=1$ - (value of stressed samples/value of normal samples). For $R_{C H L}$ calculation, $\mathrm{R}_{\mathrm{x}}=$ (value of stressed samples/value of normal samples) - 1 .

Resistance index $(\mathrm{RI})=\mathrm{DI}(\mathrm{SA}-$ pretreated samples $)$ $\mathrm{DI}$ (control samples). The RI of control seedlings is marked as number $0(\mathrm{RI}=0)$. RI $>0$ means that stress tolerance is better than the control. In contrast, $\mathrm{RI}<0$ means that the stress tolerance is worse than the control.

Antioxidant enzymes assay: A crude enzyme was extracted by the method of Wang et al. (2011). Leaves $(0.5 \mathrm{~g})$ were ground with $3 \mathrm{~cm}^{3}$ of ice-cold $25 \mathrm{mM}$ Hepes buffer ( $\mathrm{pH} 7.8$ ) containing $0.2 \mathrm{mM}$ EDTA, $2 \mathrm{mM}$ ascorbate and $2 \%(\mathrm{~m} / \mathrm{v})$ polyvinylpyrrolidone (PVP). The homogenates were centrifuged at $12000 \mathrm{~g}$ and $4{ }^{\circ} \mathrm{C}$ for $20 \mathrm{~min}$ and the resulting supernatants were used for the determination of enzyme activities at $25^{\circ} \mathrm{C}$. Protein content was determined according to Bradford (1976) with bovine serum albumin as standard.

The superoxide dismutase (SOD, E.C. 1.15.1.1) activity was assayed by measuring the ability to inhibit the photochemical reduction of nitroblue tetrazolium (Stewart and Bewley 1980). The reaction mixture contained $50 \mathrm{mM}$ sodium phosphate buffer ( $\mathrm{pH}$ 7.8), 0.1 mM EDTA, $13 \mathrm{mM}$ methionine, $75 \mu \mathrm{M}$ nitroblue tetrazolium (NBT), $2 \mu \mathrm{M}$ riboflavin and $0.02 \mathrm{~cm}^{3}$ of enzyme. One SOD unit was defined as the amount of enzyme that led to $50 \%$ inhibition of NBT reduction.

The catalase (CAT, E.C. 1.11.1.6) activity was measured by monitoring the decrease in absorbance of $\mathrm{H}_{2} \mathrm{O}_{2}$ at $240 \mathrm{~nm}$ (Beers and Sizer 1952). The reaction mixture contained $50 \mathrm{mM}$ sodium phosphate buffer (pH 7.0), $0.1 \mathrm{mM}$ EDTA, $15 \mathrm{mM} \mathrm{H}_{2} \mathrm{O}_{2}$, and $0.02 \mathrm{~cm}^{3}$ of enzyme extract. One CAT unit was defined as the amount of enzyme necessary to decompose $1 \mu \mathrm{mol} \mathrm{H}_{2} \mathrm{O}_{2}$ min $^{-1}$ under certain conditions.

The ascorbate peroxidase (APX, EC 1.11.1.11) activity was measured by the decrease in the absorbance at $290 \mathrm{~nm}$ as ascorbate was oxidized (Nakano and Asada 1981). The reaction mixture contained $50 \mathrm{mM}$ sodium phosphate buffer ( $\mathrm{pH} 7.0$ ), $0.5 \mathrm{mM}$ ascorbate, $0.1 \mathrm{mM}$ EDTA-Na $0.12 \mathrm{mM} \mathrm{H}_{2} \mathrm{O}_{2}$ and $0.020 \mathrm{~cm}^{3}$ of enzyme extract. One APX unit was defined as the amount of enzyme that oxidizes $1 \mu \mathrm{mol}$ ascorbate $\mathrm{min}^{-1}$ under certain conditions.

The guaiacol peroxidase (GPX, EC 1.11.1.9) activity was measured as the increase in the absorbance at $470 \mathrm{~nm}$ due to guaiacol oxidation (Uarrota et al. 2016). The reaction mixture contained $50 \mathrm{mM}$ sodium phosphate buffer ( $\mathrm{pH} 7.0$ ), $19 \mathrm{mM} \mathrm{H}_{2} \mathrm{O}_{2}, 9 \mathrm{mM}$ guaiacol and $0.02 \mathrm{~cm}^{3}$ of enzyme extract. One GPX unit was defined as the amount of enzyme that produce $1 \mu \mathrm{mol}$ oxidized guaiacol $\min ^{-1}$ under certain condition.

Molecular docking: To investigate the possible binding sites of SA and the cytochrome $b c l$ complex, the homology modeling of Arabidopsis cytochrome $b c 1$ complex subunit III (Swiss-Prot: P42792.2) was carried out by Swiss-Mode (https://swissmodel.expasy.org/) based on the X-ray structure of bovine cytochrome $b c l$ complex (PBD id: 1PPJ). The protein structures alignment was performed by PyMOL 2.3.1. The ligand SA was prepared and minimized with molecular operating environment (MOE 2014.0901, Chemical Computing Group). Optimization and minimization of 3-D structure of the receptor were conducted using MOE software with addition of hydrogen atoms. Protonation was employed with protonating 3D programs. Then the protein-ligand docking compute was carried out and analyzed.

Statistical analysis: Statistical analysis of the results from experiments with three or more mean values used a one-way analysis of variance $(A N O V A)$ as dictated by the number of main effects. The difference was considered to be statistically significant when $P<0.05$.

\section{Results}

To investigate the effects of SA pretreatment at different concentrations and different time points against salt stress, the four-week-old Arabidopsis seedlings were pretreated with SA and then treated with salt stress $(200 \mathrm{mM}$ $\mathrm{NaCl}$ ) for $5 \mathrm{~d}$. The electrolyte leakage, MDA and $\mathrm{H}_{2} \mathrm{O}_{2}$ content, total chlorophyll content, and resistance index were evaluated and compared among different samples (Table 1 Suppl., Fig. 1 Suppl.). Results showed that lower concentrations of SA $(10$ and $20 \mu \mathrm{M})$ significantly promoted plant salt stress tolerance, whereas pretreatment with higher concentrations of SA (especially $200 \mu \mathrm{M}$ ) impaired plant resistance to salt stress. However, it should be noted that the promotion effects of lower concentration of SA on plant stress acclimation were in a time-dependent manner. For example, there was no significant difference between $10 \mu \mathrm{M}$ SA-pretreated seedlings and the control seedlings if they were subjected to the salt stress after 2 or 
$4 \mathrm{~h}$ pretreatment. The best promotion effects of $10 \mu \mathrm{M} \mathrm{SA}$ pretreatment in plant resistance to salt stress occurred after 8 - $18 \mathrm{~h}$. In comparison, the $20 \mu \mathrm{M}$ SA-pretreated seedlings displayed stronger resistance to salt stress than the control as well as the $10 \mu \mathrm{M}$ SA-pretreated seedlings when they were expososed to salt stress after $6 \mathrm{~h}$. However, if the seedlings were pretreated with $20 \mu \mathrm{M}$ SA only for 2 or $4 \mathrm{~h}$, they were more vulnerable to damage than the control. Similarly, seedlings pretreated with $50 \mu \mathrm{M}$ SA for 2 to $14 \mathrm{~h}$ showed serious damage when exposed to salt stress, but, after $22 \mathrm{~h}$ of pretreatment with $50 \mu \mathrm{M}$ SA, the seedlings showed a little higher stress tolerance than the control (Fig. 1). In addition, $200 \mu \mathrm{M}$ SA pretreatment reduced the plant resistance to salt stress in each time point (Fig. 1). These results indicated that lower concentrations of SA pretreatment were beneficial for the plant tolerance to salt stress, but the promotion effects were time-dependent.

Previous work demonstrated that SA application may inhibit the plant mitochondrial respiration directly or indirectly (Xie and Chen 1999, Norman et al. 2004). Therefore, respiratory rate assay after different concentrations of SA pretreatment was investigated. As shown in Fig. $2 A$, all concentrations of SA pretreatment repressed the total respiration rates $\left(V_{\mathrm{t}}\right)$, but at different levels. It should be noted that $V_{\mathrm{t}}$ was also inhibited by the pretreatment with $10 \mu \mathrm{M}$ SA and $20 \mu \mathrm{M}$ SA during the first $4 \mathrm{~h}$. In comparison, the $V_{\mathrm{t}}$ inhibition observed in the seedlings pretreated by $20 \mu \mathrm{M}$ SA was more severe than that observed in the seedlings pretreated by $10 \mu \mathrm{M}$ SA during the first $4 \mathrm{~h}$, although they showed similar trend in $V_{\mathrm{t}}$. There was significant $V_{\mathrm{t}}$ inhibition occurred in $50 \mu \mathrm{M}$ $\mathrm{SA}$-pretreated seedlings during the first $10 \mathrm{~h}$, and then the $V_{\mathrm{t}}$ gradually recovered but remained lower than control in the following time.

As shown in Fig. 2B, SA pretreatments inhibited the
$V_{\mathrm{t}}$ while promoted the AOX pathway respiration $\left(V_{\text {alt }}\right)$. In contrast, the seedlings pretreated with $200 \mu \mathrm{M}$ SA had the highest induction rate of $V_{\text {alt }}$ during the first $12 \mathrm{~h}$ but the lowest $V_{\text {alt }}$ during the whole experiment (Fig. 2C). For $50 \mu \mathrm{M}$ SA-pretreated seedlings, the $V_{\text {alt }}$ was induced significantly but the $V_{\mathrm{t}}$ was lower than in the 10 or $20 \mu \mathrm{M}$ SA-pretreated seedlings and control during the first $20 \mathrm{~h}$. Interestingly, it should be noted that the $V_{\text {alt }}$ of $20 \mu \mathrm{M}$ SApretreated seedlings was much higher than that of $10 \mu \mathrm{M}$ SA-pretreated seedlings during the whole experiment (Fig. $2 B$ ), although they maintained the same $V_{\mathrm{t}}$ as control after $6 \mathrm{~h}$ of SA pretreatments (Fig. $2 A$ ).

To investigate the effects of AOX inhibition on the SAmediated plant salt stress acclimation, SHAM (an inhibitor for AOX) was used in the following experiment (Fig. 3). All the SHAM-pretreated seedlings were more sensitive to salt stress than the control and SA-pretreated seedlings. Moreover, the resistance to salt stress induced by 10 or $20 \mu \mathrm{M}$ SA was impaired by $1 \mathrm{mM}$ SHAM, and the RI was even lower than in the control (Fig. 3). It should be noted that the seedlings pretreated with $50 \mu \mathrm{M}$ SA plus $1 \mathrm{mM}$ SHAM exhibited terrible oxidative damage under salt stress, and the RI was five-fold lower than in the $50 \mu \mathrm{M}$ SA-pretreated seedlings and even two-fold lower than in the $200 \mu \mathrm{M}$ SA-pretreated seedlings (Fig. 3). Thus, the most serious oxidative damage (lowest RI) was observed in the seedlings pretreated with $200 \mu \mathrm{M}$ SA plus $1 \mathrm{mM}$ SHAM (Fig. 3). These results indicated the importance of AOX in plant stress acclimation as well as in SA-mediated plant stress adaptation.

However, it should be noted that the plant resistance was slightly higher when the SHAM-pretreated seedlings were subjected to salt stress after 12 h (Fig. 3). Typically, the RI of SA $(10$ or $20 \mu \mathrm{M})$ and SHAM co-pretreated seedlings increased gradually if they were transferred

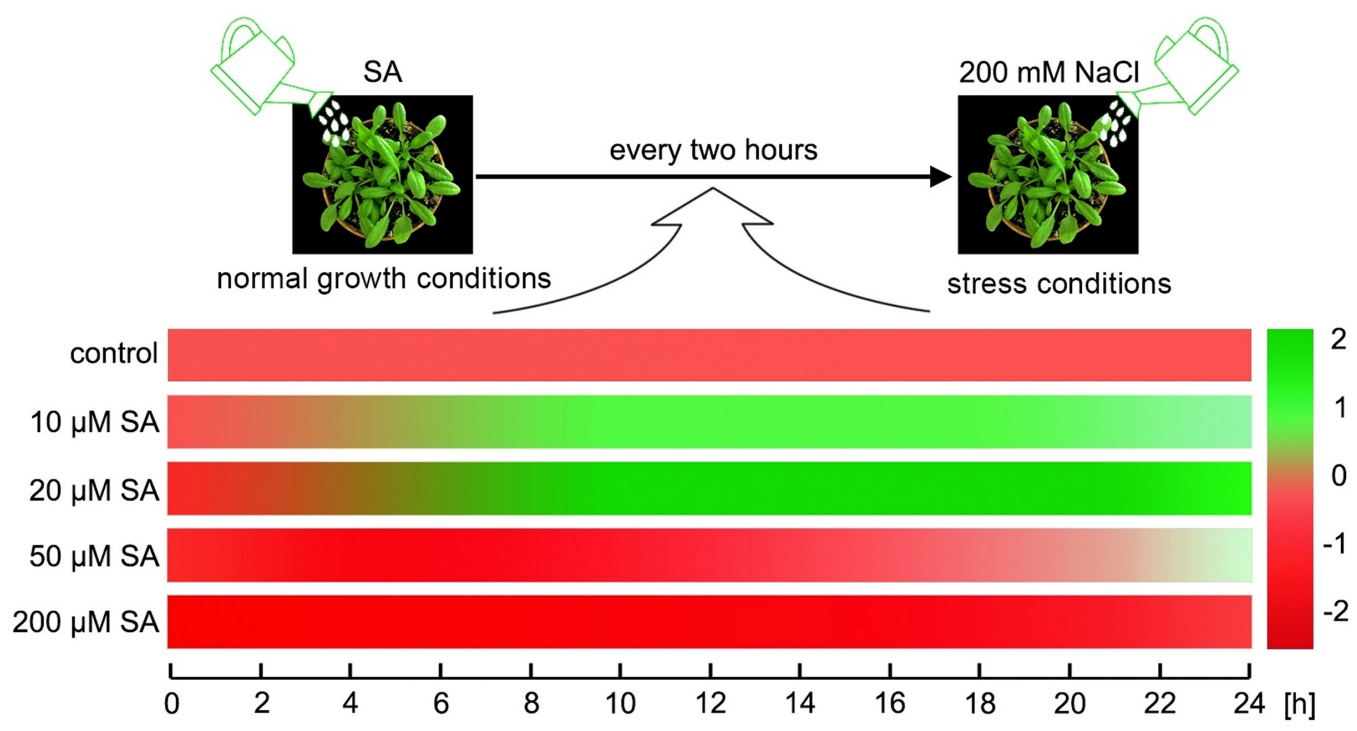

Fig. 1. Effects of salicylic acid (SA) pretreatment at different concentrations and times on the salt stress resistance of Arabidopsis. Fourweek-old seedlings were sprayed with different concentrations of SA and the control with water, and then every $2 \mathrm{~h}$ a group of seedlings was transferred to $200 \mathrm{mM} \mathrm{NaCl}$ (salt stress). After $5 \mathrm{~d}$, the plant oxidative damage was measured for evaluating the resistance index (RI). Different colors represent different RIs of seedlings, of which green represents a better RI and red represents a weaker RI. 
to salt stress after $12 \mathrm{~h}$. Further, SA + SHAM pretreated seedlings exhibited better adaptation to the salt stress than the SHAM-pretreated seedlings, although their RI values were still lower than that of the SA-pretreated seedlings and even the control (Fig. 3). Accordingly, there should be some other resistance factors besides AOX, which were directly or indirectly induced by the lower concentrations of SA.
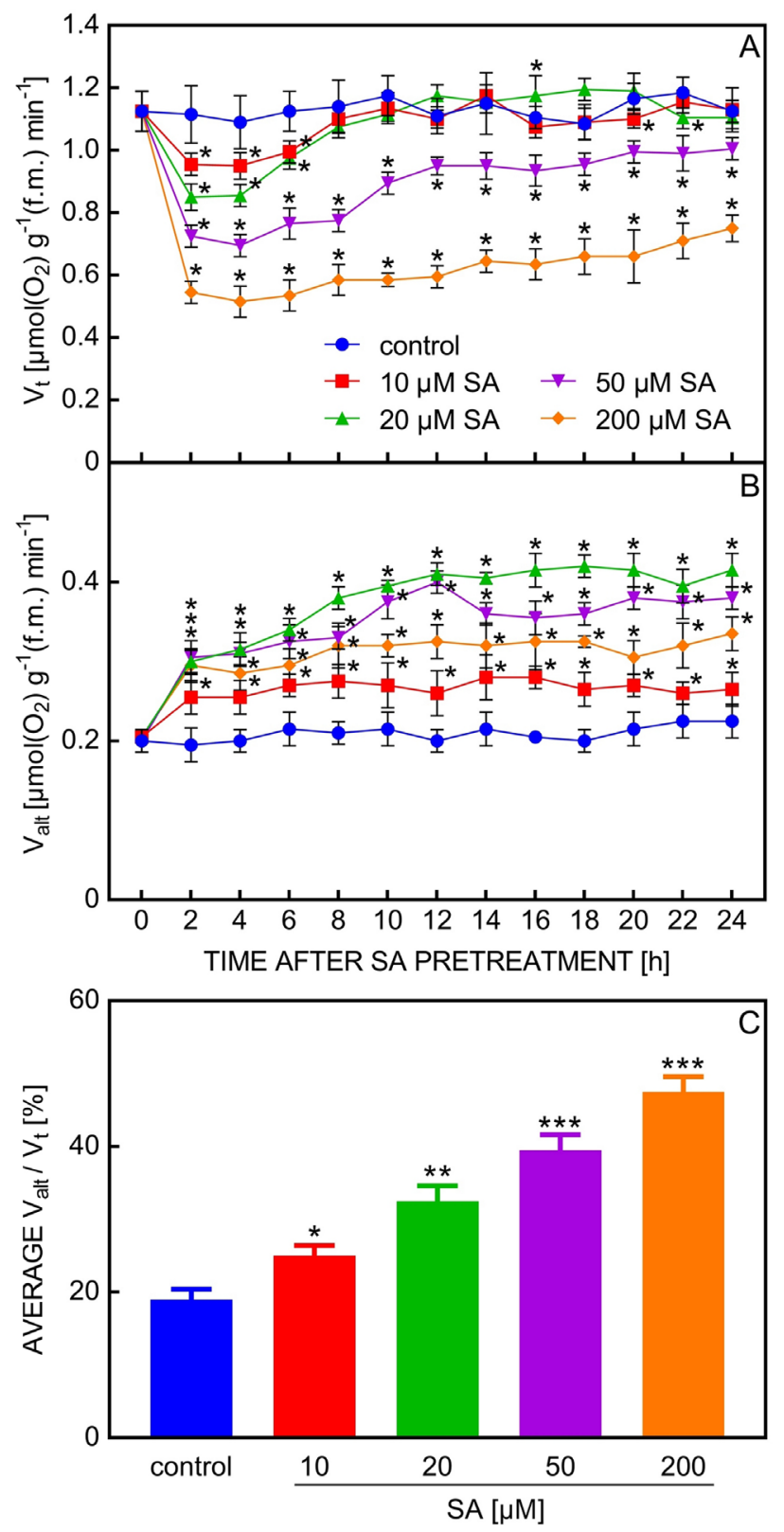

Fig. 2. Changes in respiration rates after pretreatment with different concentrations of salicylic acid (SA). Every two hours, $\mathrm{V}_{\mathrm{t}}(A)$ and $\mathrm{V}_{\text {alt }}(B)$ were detected using Clark-type electrodes. In addition, the average data of $V_{\text {alt }}$ and $V_{t}$ during the first $24 \mathrm{~h}$ after SA pretreatment were calculated and the $\mathrm{V}_{\mathrm{alt}} / \mathrm{V}_{\mathrm{t}}$ ratio was compared between different samples $(C)$. $\mathrm{V}_{\mathrm{t}}$ - total respiration, $\mathrm{V}_{\text {alt }}$ - alternative oxidase pathway respiration. Means \pm SDs of three independent experiments. Asterisks represent statistical differences relative to a control at the same time point $(*-P<0.05, * *-P<0.01, * * * P-<0.001)$.
It was shown that inhibition of mitochondrial respiration causes increased production of ROS, which could be scavenged by enzymatic antioxidants to protect plants from oxidative damage (Choudhury et al. 2017). Since SA pretreatments were shown to inhibit the $V_{t}$, thus the ROS production and the activities of antioxidant enzymes including SOD, CAT, APX, and GPX were investigated then. The results showed that SA pretreatments induced the $\mathrm{H}_{2} \mathrm{O}_{2}$ generation in a dose-dependent manner (Fig. 4A). Lower concentrations of SA $(10$ or $20 \mu \mathrm{M})$ increased the $\mathrm{H}_{2} \mathrm{O}_{2}$ generation during the first $8 \mathrm{~h}$, but then decreased to the same level as control. The pretreatment with $50 \mu \mathrm{M}$ SA induced higher amount of $\mathrm{H}_{2} \mathrm{O}_{2}$ than 10 or $20 \mu \mathrm{M} \mathrm{SA}$, while less $200 \mu \mathrm{M}$ SA pretreatment. The amount of $\mathrm{H}_{2} \mathrm{O}_{2}$ in $200 \mu \mathrm{M}$ SA-pretreated seedlings was about four times higher than that of control seedlings during the first $12 \mathrm{~h}$ (Fig. 4A).

There were significant increases in activities of SOD, CAT, APX, and GPX after pretreatment with 10 or $20 \mu \mathrm{M}$ $\mathrm{SA}$ for $4 \mathrm{~h}$ compared to control (Fig. $4 B-E$ ). Among them, the activities of SOD, CAT, and APX maintained high also after $10 \mathrm{~h}$ pretreatment. The activities of antioxidant enzymes in $20 \mu \mathrm{M}$ SA-pretreated seedlings were higher than those of the $10 \mu \mathrm{M}$ SA-pretreated seedlings, especially for the SOD and APX. Pretreatment with $50 \mu \mathrm{M}$ SA also promoted the activities of SOD, CAT, APX, and GPX after $2 \mathrm{~h}$, and the they were a little higher than those of 10 or $20 \mu \mathrm{M}$ SA-pretreated seedlings. Moreover, significant increases in the activities of antioxidant enzymes were found in $200 \mu \mathrm{M}$ SA-pretreated seedlings during the first $10 \mathrm{~h}$, but they decreased sharply after that, especially for the CAT, APX, and GPX.

Considering our results and previous reports mentioned that SA could inhibit cytochrome pathway respiration, especially the state 3 respiration (Norman et al. 2004), but little information is available on how SA affects the electron transport via the cytochrome pathway. Therefore, we tried to analyze the docking sites of SA in Arabidopsis cytochrome $b c 1$ complex. As shown in Fig. 2 Suppl., the homology model of Arabidopsis cytochrome bcl complex subunit 3 was generated and the protein-ligand (SA) docking computation was carried out. Results showed that SA can bind to the cytochrome $b$ heme center and the gate of quinone reduction (Qi) tunnel (Fig. 5A,B), which is similar to the binding site of antimycin A (a typical inhibitor of cytochrome $b c 1$ ). In addition, the chemical structure alignment showed that antimycin A has a headgroup consisting of 3-formylamino salicylate, that is similar to the chemical structure of SA (Fig. 5C).

\section{Discussion}

The effect of exogenous SA on the stress tolerance of plants is not always obvious (Horváth et al. 2007). In this study, efforts were made to improve our understanding of the influences of the different pretreatment times with different concentrations of SA on the response of Arabidopsis seedlings to salt stress induced by $200 \mathrm{mM} \mathrm{NaCl}$ for $5 \mathrm{~d}$. Interestingly, we found that SA has both promotive and 
inhibitory effects on plant salt stress tolerance, depending not only on the concentration applied but also on the duration of pretreatment.

Our study indicates that the transient and small amounts of ROS induced by lower concentrations of SA (10 and $20 \mu \mathrm{M}$ ) plays a pivotal role in plant stress resistance, although some previous studies have shown that lower concentrations of SA $(0.01-0.05 \mathrm{mM})$, do not effectively induce ROS accumulation (Kumar et al. 2015). To explain this, we speculate that the time to detect ROS content is critical to understanding the relationship between SA and ROS production. In this study, the data showed that the ROS content in 10 or $20 \mu \mathrm{M}$ SA-pretreated seedlings decreased to the same level as in the control after $6 \mathrm{~h}$ of pretreatment. Additionally, according to the result of SA docking computation with $M O E$, we found that SA can bind to the Qi site of cytochrome $b c l$ complex, which is similar to the binding site of antimycin A. It is known that antimycin $\mathrm{A}$, one of the first known and most potent inhibitors of the mitochondrial respiratory chain, binds to the Qi site of the cytochrome bcl complex (Huang et al. 2005, Ransac and Mazat 2010). Notably, antimycin A has a headgroup consisting of 3-formylamino salicylate, which is similar to the chemical structure of SA. So it is possible that SA affects Q-cycle by preventing the return of the electron from haem bH to Qi, which directly or indirectly affects the ROS production. The study of De Souza et al. (2011) proposed that SA inhibits the electron transport chain by inactivation of the semiquinone radical in the Q cycle. However, more research is needed to reveal the mechanism of SA-mediated respiration inhibition in cytochrome $b c l$ complex and the protein crystallization with SA should be able to achieve it.

Additionally, the evidence in this study indicates that
SA does not only play a pro-oxidant role, but it also has an antioxidant role in concert with antioxidant enzymes. Consistent with previous studies, Horváth et al. (2007) reported that a rapid transient increase in ROS is followed by enhanced antioxidative capacity, which protects the plant from the severe damage. Similarly, Hossain et al. (2015) stated that $\mathrm{H}_{2} \mathrm{O}_{2}$ priming induces mild oxidative stress by disruption of cellular ROS homeostasis, but induces the accumulation of latent defense proteins including ROSscavenging enzymes, resulting in a primed state and enhanced subsequent stress responses. Conversely, the enhanced sensitivity of plants to environmental stress was generally associated with the reduced ROS-scavenging ability (Das and Roychoudhury 2014, Hossain et al. 2015).

Pretreatment with $50 \mu \mathrm{M}$ SA also stimulated the activities of antioxidant enzymes, but the seedlings were less adaptable to salt stress than the control seedlings, especially when the pretreated seedlings were subjected to salt stress after 2 to $12 \mathrm{~h}$. This case might be attributed to the stronger inhibition of respiration rate and a higher rate of ROS generation observed in $50 \mu \mathrm{M}$ SA-pretreated seedlings, compared to 10 or $20 \mu \mathrm{M}$ SA-pretreated seedlings and control seedlings, leading to a decrease in the capacity to scavenge ROS within a short time and more serious oxidative damage happened when they suffered from salt stress. Higher concentrations of ROS cause an oxidative stress that the plant is unable to overcome and which may result in the death of the plant (Overmyer et al. 2003, Horváth et al. 2007). Consequently, it is not difficult to explain why the $200 \mu \mathrm{M}$ SA-pretreated seedlings were more sensitive to salt stress because more ROS were generated compared to the other pretreated seedlings. Moreover, in $200 \mu \mathrm{M}$ SA-pretreated seedlings, the initial delayed induction of activities of antioxidant enzymes and

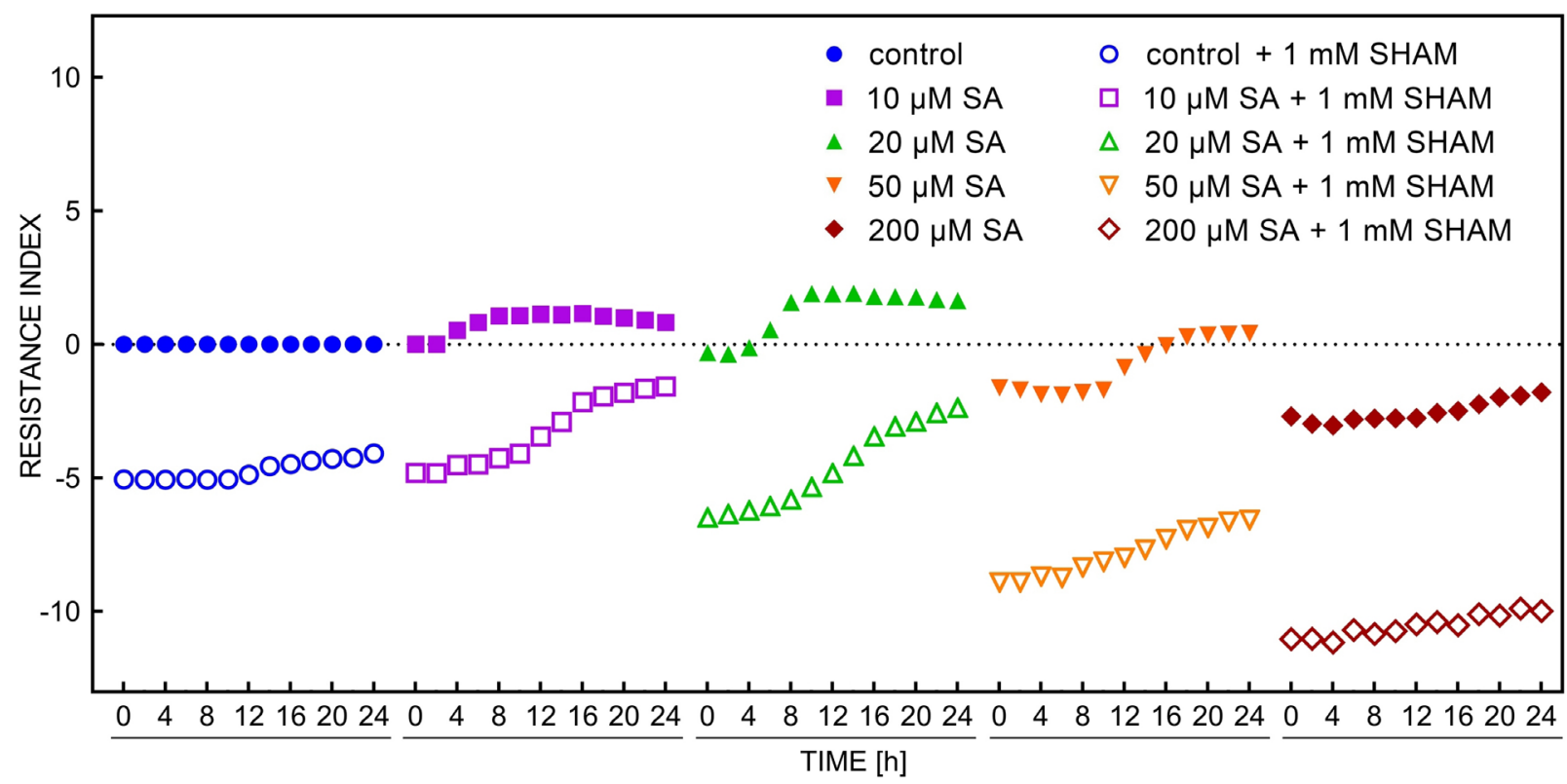

Fig. 3. Comparison of salt stress resistance with or without (SHAM) treatment. The 4-week-old seedlings were pretreated with different concentrations of SA $(10,20,50,200 \mu \mathrm{M})$ with or without additional of $1 \mathrm{mM}$ salicylhydroxamic acid (SHAM). Then, every $2 \mathrm{~h}$ the pretreated seedlings were transferred to $200 \mathrm{mM} \mathrm{NaCl}$. The resistance index was evaluated after $5 \mathrm{~d}$ of salt stress. Means of three independent experiments. 
rapid decline after $10 \mathrm{~h}$ may be one of the main reasons for the higher ROS accumulation in these seedlings. Under stressful conditions, when the level of ROS rises above the threshold value, oxidative burst associated with lipid peroxidation (i.e. MDA) and ion leakage is harmful to the plant survival (Das and Roychoudhury 2014, Pospíšil and Yamamoto 2017).

In this study, AOX was certainly involved in SAmediated plant growth and stress tolerance. AOX is found in all plants and is insensitive to inhibitors of the cytochrome oxidase pathway (Moore et al. 2002). The involvement of $\mathrm{AOX}$ in the response to salinity stress has been evident in early studies where an increase in the AOX capacity was demonstrated to be responsible for decreasing ROS production in plant cells (Matos et al. 2009). It appears that there should be a link between AOX capacity and ROS formation in response to salt stress of SA-mediated plants (Fig. 3 Suppl.). Here we found that inhibition of AOX activity by SHAM compromised the lower concentrations of SA-mediated salt stress resistance, suggesting that AOX played an important role in stress acclimation and also in SA-mediated stress tolerance. Since $\mathrm{SA}$ is an inhibitor of mitochondrial electron transport and it caused the concentration-dependent induction of AOX capacity, it appears that AOX contributes to reduce ROS accumulation caused by SA pretreatment. AOX is thought to induced by SA and assist in minimizing the production of ROS by the respiratory chain (Maxwell et al. 2002). Nevertheless, the relationship between SA and AOX is still unclear, especially whether AOX is directly or indirectly induced by SA remains to be confirmed by further research.

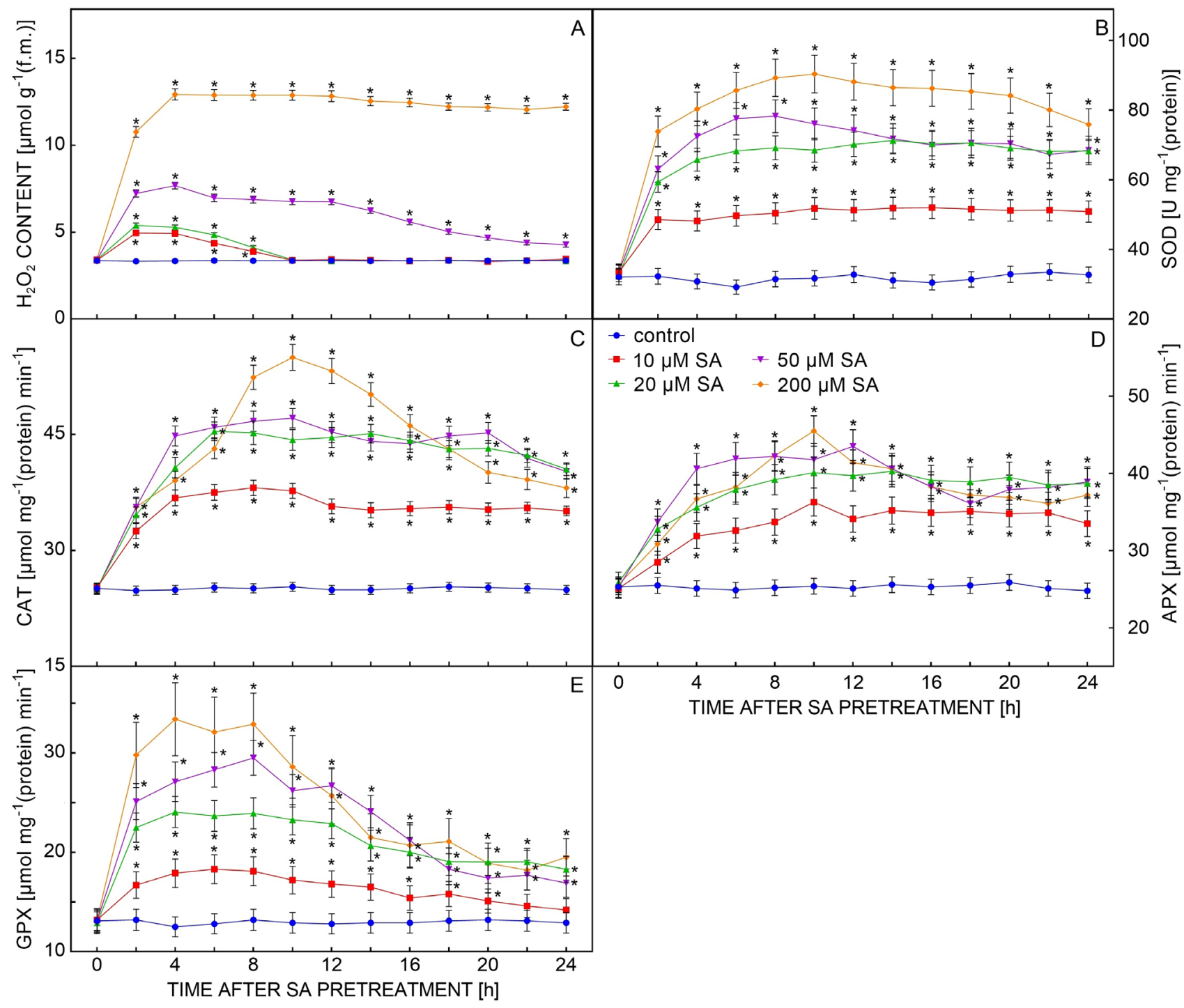

Fig. 4. Changes in $\mathrm{H}_{2} \mathrm{O}_{2}$ content $(A)$ and antioxidant enzyme activities $(B-E)$ after pretreatment with different concentrations of salicylic acid (SA). Every $2 \mathrm{~h}$ the pretreated seedlings were transferred to $200 \mathrm{mM} \mathrm{NaCl}$ for $5 \mathrm{~d}$. In this experiment, $\mathrm{H}_{2} \mathrm{O}_{2}$ content and activities of antioxidant enzymes including superoxide dismutase (SOD), catalase (CAT), ascorbate peroxidase (APX), and guiacol peroxidase (GPX) were determined. Means \pm SDs of three independent experiments. Asterisks represent significant differences relative to a control at the same time point $(P<0.05)$. 

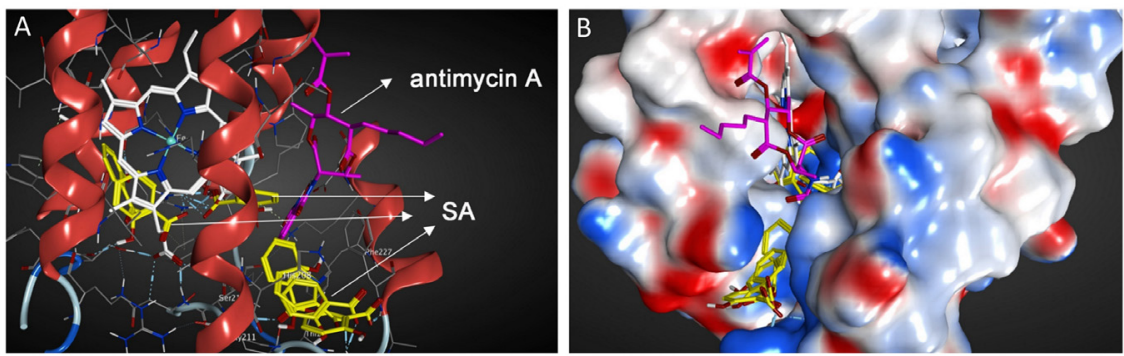

C
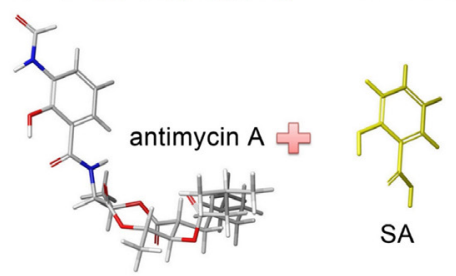

alignment

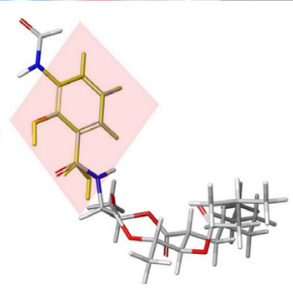

Fig. 5. The possible docking sites of salicylic acid (SA) in Arabidopsis cytochrome bcl complex subunit 3. A cartoon model (A) and a surface model $(B)$ of the docking sites of SA in a receptor protein. The molecular docking analysis was performed with the molecular operating environment (MOE2014.0901) software. In the cartoon model, the yellow-colored ligand is SA and the purple-colored one is antimycin A. In the surface model, residues of receptor are colored according to the electrostatic potential. $C$ - Comparison of the chemical structure between SA and antimycin A.

\section{Conclusions}

In short, it is evident that application of SA might be beneficial for plant resistance to environmental stress but the utility of SA depends on the plant species, developmental stage, and the SA concentrations (Wani et al. 2016). However, in this study, not only the SA concentration but also pretreatment duration is importance for alleviating salinity stress. For example, pretreatment with 10 or $20 \mu \mathrm{M}$ SA contributed to the plants salt stress acclimation only if the SA pretreatment was not less than $6 \mathrm{~h}$ and not more than $24 \mathrm{~h}$. Thus, our findings provide some valuable insights into the correlation between the establishment of plant stress resistance and SA applied concentrations and times, which are not only beneficial for further understanding the role of SA in plant response to stress, but also for the possible application of SA in improving the stress tolerance of important crops.

\section{References}

Ashraf, M., Akram, N., Arteca, R., Foolad, M.: The physiological, biochemical and molecular roles of brassinosteroids and salicylic acid in plant processes and salt tolerance. - Crit. Rev. Plant Sci. 29: 162-190, 2010.

Bai, X., Dong, Y., Kong, J., Xu, L., Liu, S.: Effects of application of salicylic acid alleviates cadmium toxicity in perennial ryegrass. - Plant Growth Regul. 75: 695-706, 2015.

Beers, R.F., Jr., Sizer, I.W.: A spectrophotometric method for measuring the breakdown of hydrogen peroxide by catalase. J. biol. Chem. 195: 133-140, 1952.

Borsani, O., Valpuesta, V., Botella, M.A.: Evidence for a role of salicylic acid in the oxidative damage generated by nacl and osmotic stress in Arabidopsis seedlings. - Plant Physiol. 126: 1024-1030, 2001.

Bradford, M.M.: A rapid and sensitive method for the quantitation of microgram quantities of protein utilizing the principle of protein-dye binding. - Anal. Biochem. 72: 248-254, 1976.

Cao, Y., Zhang, Z.W., Xue, L.W., Du, J.B., Shang, J., Xu, F., Yuan, S., Lin, H.H.: Lack of salicylic acid in Arabidopsis protects plants against moderate salt stress. - Z. Naturforsch. 64: 231-238, 2009

Choudhury, F.K., Rivero, R.M., Blumwald, E., Mittler, R.: Reactive oxygen species, abiotic stress and stress combination. - Plant J. 90: 856-867, 2017.

Das, K., Roychoudhury, A.: Reactive oxygen species (ROS) and response of antioxidants as ROS-scavengers during environmental stress in plants. - Front. Environ. Sci. 2: 2014.

De Souza, W.R., Vessecchi, R., Dorta, D.J., Uyemura, S.A., Curti, C., Vargas-Rechia, C.G.: Characterization of Rubus fruticosus mitochondria and salicylic acid inhibition of reactive oxygen species generation at Complex III/Q cycle: potential implications for hypersensitive response in plants. J. Bioenerg. 43: 237-246, 2011.

Fragniere, C., Serrano, M., Abou-Mansour, E., Metraux, J.P., L'Haridon, F.: Salicylic acid and its location in response to biotic and abiotic stress. - FEBS Lett. 585: 1847-1852, 2011.

Gilliland, A., Singh, D.P., Hayward, J.M., Moore, C.A., Murphy, A.M., York, C.J., Slator, J., Carr, J.P.: Genetic modification of alternative respiration has differential effects on antimycin A-induced versus salicylic acid-induced resistance to Tobacco mosaic virus. - Plant Physiol. 132: 1518-1528, 2003.

Horváth, E., Csiszár, J., Gallé, Á., Poór, P., Szepesi, Á., Tari, I.: Hardening with salicylic acid induces concentrationdependent changes in abscisic acid biosynthesis of tomato under salt stress. - J. Plant Physiol. 183: 54-63, 2015.

Horváth, E., Szalai, G., Janda, T.: Induction of abiotic stress tolerance by salicylic acid signaling. - J. Plant Growth Regul. 26: 290-300, 2007.

Hossain, M.A., Bhattacharjee, S., Armin, S.M., Qian, P., Xin, W., Li, H.Y., Burritt, D.J., Fujita, M., Tran, L.S.: Hydrogen peroxide priming modulates abiotic oxidative stress tolerance: insights from ROS detoxification and scavenging. - Front. Plant Sci. 6: 420, 2015.

Huang, L.S., Cobessi, D., Tung, E.Y., Berry, E.A.: Binding of the respiratory chain inhibitor antimycin to the mitochondrial bc1 complex: a new crystal structure reveals an altered 
intramolecular hydrogen-bonding pattern. - J. mol. Biol. 351: 573-597, 2005.

Jayakannan, M., Bose, J., Babourina, O., Rengel, Z., Shabala, S.: Salicylic acid in plant salinity stress signalling and tolerance. - Plant Growth Regul. 76: 25-40, 2015.

Khan, S.U., Bano, A., Gurmani, A.: Abscisic acid and salicylic acid seed treatment as potent inducer of drought tolerance in wheat (Triticum aestivum L.). - Pak. J. Bot. 44: 43-49, 2012.

Kumar, D., Chapagai, D., Dean, P., Davenport, M.: Biotic and abiotic stress signaling mediated by salicylic acid. - In: Pandey, G.K. (ed.): Elucidation of Abiotic Stress Signaling in Plants. Pp. 329-346. Springer, New York 2015.

Lee, S., Kim, S.G., Park, C.M.: Salicylic acid promotes seed germination under high salinity by modulating antioxidant activity in Arabidopsis. - New Phytol. 188: 626-637, 2010.

Lichtenthaler, H.K., Wellburn, A.R.: Determinations of total carotenoids and chlorophylls $a$ and $b$ of leaf extracts in different solvents. - Biochem. Soc. Trans. 11: 591-592, 1983.

Matos, A.R., Mendes, A.T., Scotti-Campos, P., Arrabaça, J.D.: Study of the effects of salicylic acid on soybean mitochondrial lipids and respiratory properties using the alternative oxidase as a stress-reporter protein. - Physiol. Plant 137: 485-497, 2009.

Maxwell, D.P., Nickels, R., McIntosh, L.: Evidence of mitochondrial involvement in the transduction of signals required for the induction of genes associated with pathogen attack and senescence. - Plant J. 29: 269-279, 2002.

Miura, K., Okamoto, H., Okuma, E., Shiba, H., Kamada, H., Hasegawa, P.M., Murata, Y.: SIZ1 deficiency causes reduced stomatal aperture and enhanced drought tolerance via controlling salicylic acid-induced accumulation of reactive oxygen species in Arabidopsis. - Plant J. 73: 91-104, 2013.

Miura, K., Tada, Y.: Regulation of water, salinity, and cold stress responses by salicylic acid. - Front. Plant Sci. 5: 4, 2014.

Moore, A.L., Albury, M.S., Crichton, P.G., Affourtit, C.: Function of the alternative oxidase: is it still a scavenger? - Trends Plant Sci. 7: 478-481, 2002.

Nakano, Y., Asada, K.: Hydrogen peroxide is scavenged by ascorbate-specific peroxidase in spinach chloroplasts. - Plant Cell Physiol. 22: 867-880, 1981.

Nazar, R., Iqbal, N., Syeed, S., Khan, N.A.: Salicylic acid alleviates decreases in photosynthesis under salt stress by enhancing nitrogen and sulfur assimilation and antioxidant metabolism differentially in two mungbean cultivars. - J. Plant Physiol. 168: 807-815, 2011.

Norman, C., Howell, K.A., Millar, A.H., Whelan, J.M., Day, D.A.: Salicylic acid is an uncoupler and inhibitor of mitochondrial electron transport. - Plant Physiol. 134: 492-501, 2004.

Okuma, E., Nozawa, R., Murata, Y., Miura, K.: Accumulation of endogenous salicylic acid confers drought tolerance to Arabidopsis. - Plant Signal Behav. 9: e28085, 2014.

Overmyer, K., Brosché, M., Kangasjärvi, J.: Reactive oxygen species and hormonal control of cell death. - Trends Plant Sci. 8: 335-342, 2003.

Pál, M., Szalai, G., Kovács, V., Gondor, O.K., Janda, T.: Salicylic acid-mediated abiotic stress tolerance. - In: Hayat, S., Ahmad, A., Alyemeni, M.N. (ed.): Salicylic Acid: Plant Growth and Development.Ppp. 183-247. Springer, Dordrecht 2013.

Palma, F., López-Gómez, M., Tejera, N., Lluch, C.: Salicylic acid improves the salinity tolerance of Medicago sativa in symbiosis with Sinorhizobium meliloti by preventing nitrogen fixation inhibition. - Plant Sci. 208: 75-82, 2013.

Pospíšil, P., Yamamoto, Y.: Damage to photosystem II by lipid peroxidation products. - Biochim. biophys. Acta 1861: 457466, 2017.

Ransac, S., Mazat, J.P.: How does antimycin inhibit the $b c 1$ complex? A part-time twin. - Biochim. biophys. Acta 1797: 1849-1857, 2010.

Sawada, H., Shim, I.-S., Usui, K.: Induction of benzoic acid 2-hydroxylase and salicylic acid biosynthesis - modulation by salt stress in rice seedlings. - Plant Sci. 171: 263-270, 2006.

Scott, I.M., Clarke, S.M., Wood, J.E., Mur, L.A.: Salicylate accumulation inhibits growth at chilling temperature in Arabidopsis. - Plant Physiol. 135: 1040-1049, 2004.

Sharma, P.: Salicylic acid: a novel plant growth regulator - role in physiological processes and abiotic stresses under changing environments. - In: Tuteja, N., Gill, S.S. (ed.): Climate Change and Plant Abiotic Stress Tolerance. Pp. 939-990. Wiley, Weinheim 2014.

Singh, A.P., Dixit, G., Mishra, S., Dwivedi, S., Tiwari, M., Mallick, S., Pandey, V., Trivedi, P.K., Chakrabarty, D., Tripathi, R.D.: Salicylic acid modulates arsenic toxicity by reducing its root to shoot translocation in rice (Oryza sativa L.). - Front. Plant Sci. 6: 340, 2015.

Stevens, J., Senaratna, T., Sivasithamparam, K.: Salicylic acid induces salinity tolerance in tomato (Lycopersicon esculentum cv. Roma): associated changes in gas exchange, water relations and membrane stabilisation. - Plant Growth Regul. 49: 77-83, 2006.

Stewart, R.R., Bewley, J.D.: Lipid peroxidation associated with accelerated aging of soybean axes. - Plant Physiol. 65: 245248, 1980.

Sun, X., Yuan, S., Lin, H.H.: Salicylic acid decreases the levels of dehydrin-like proteins in Tibetan hulless barley leaves under water stress. - Z. Naturforsch. 61: 245-250, 2006.

Szepesi, Á., Csiszár, J., Gémes, K., Horváth, E., Horváth, F., Simon, M.L., Tari, I.: Salicylic acid improves acclimation to salt stress by stimulating abscisic aldehyde oxidase activity and abscisic acid accumulation, and increases $\mathrm{Na}^{+}$content in leaves without toxicity symptoms in Solanum lycopersicum L. - J. Plant Physiol. 166: 914-925, 2009.

Uarrota, V.G., Moresco, R., Schmidt, E.C., Bouzon, Z.L., Nunes Eda, C., Neubert Ede, O., Peruch, L.A., Rocha, M., Maraschin, M.: The role of ascorbate peroxidase, guaiacol peroxidase, and polysaccharides in cassava (Manihot esculenta Crantz) roots under postharvest physiological deterioration. - Food Chem. 197: 737-746, 2016.

Velikova, V., Yordanov, I., Edreva, A.: Oxidative stress and some antioxidant systems in acid rain-treated bean plants: protective role of exogenous polyamines. - Plant Sci. 151: 59-66, 2000.

Verma, V., Ravindran, P., Kumar, P.P.: Plant hormone-mediated regulation of stress responses. - BMC Plant Biol. 16: 86, 2016.

Wang, S.D., Zhu, F., Yuan, S., Yang, H., Xu, F., Shang, J., Xu, M.Y., Jia, S.D., Zhang, Z.W., Wang, J.H., Xi, D.H., Lin, H.H.: The roles of ascorbic acid and glutathione in symptom alleviation to SA-deficient plants infected with RNA viruses. - Planta 234: 171-181, 2011.

Wani, A.B., Chadar, H., Wani, A.H., Singh, S., Upadhyay, N.: Salicylic acid to decrease plant stress. - Environ. Chem. Lett. 15: 101-123, 2016.

Wasti, S., Mimouni, H., Smiti, S., Zid, E., Ben Ahmed, H.: Enhanced salt tolerance of tomatoes by exogenous salicylic acid applied through rooting medium. - Omics 16: 200-207, 2012.

Xie, Z., Chen, Z.: Salicylic acid induces rapid inhibition of mitochondrial electron transport and oxidative phosphorylation in tobacco cells. - Plant Physiol. 120: 217 226, 1999.

Xu, F., Zhang, D.W., Zhu, F., Tang, H., Lv, X., Cheng, J., Xie, H.F., Lin, H.H.: A novel role for cyanide in the control of cucumber (Cucumis sativus L.) seedlings response to environmental stress. - Plant Cell Environ. 35: 1983-1997, 2012. 